\title{
Gestão Adaptativa e Sustentável para a Restauração de Rios: Parte I Enfoques Teóricos sobre Capacitação Social
}

\author{
Maria Camerina Maroja Limeira, Tarciso Cabral da Silva \\ UniversidadeFederal da Paraíba \\ marojalimeira@yahoo.com.br, tarcisocabral@yahoo.com.br \\ Gesinaldo Ataíde Cândido \\ Universidade Federal de Campina Grande \\ gacandido@uol.com.br
}

Recebido: 19/03/08 - revisado: 08/02/09 - aceito: 08/12/09

\begin{abstract}
RESUM 0
Os princípios de descentralização, integração e participação, indispensáveis à eficácia do processo de gestão dos recursos hídricos, tornam-se difícess de serem exercidos plenamente devido à clara situação predominante relativa à falta de investimentos em capacitação social. Enten dese capacitação social como a capacidade de in divídu os, gru pos e instituições produzirem resultados desejáveis. Como um processo de constru ção de um sistema, no qual se alcançam as capacidades técnica, gerencial e financeira, a capacitação social é vista como uma estratégia que pode ser desenvolvida através de uma gestão aberta e adaptativa. Essa estratégia gerencial é revisada e analisada neste trabalho sob a perspectiva de possibilitar maior credibilidade e confiança aos gestores de projetos na área ambiental, especialmente em projetos de restau ração de rios. É ressaltado o papel do Estado na tentativa de se obter a convergência de conceitos e a coerên cia de ações como u ma etapa preliminar fundamental na busca pela eficiência da gestão de projetos de restauração de cursos d'água.
\end{abstract}

Palavras-chave: restau ração de rios, capacitação social, gestão estratégica.

\section{INTRO DUÇÃO}

Face à necessidade de acompanhar as grandes questões mundiais relativas a fortalecer a economia de cada país baseada nos princípios de desenvolvimento sustentável, o Brasil se propõe a procurar assegurar sua prosperidade econômica, como também a qualidade de vida dos seus cidadãos no presente e no futuro. Dessa forma, em longo prazo, os governos, a indústria, a agricultura, o comércio e os serviços produzidos no país deverão, em conjunto, absorver responsabilidades compartilhadas e produzir resultados comuns.

Nesse contexto, uma das prioridades da política nacional do meio ambiente, em consonância com as demais políticas de recursos naturais, como a de recursos hídricos, florestais e agrícolas, é manter nosso patrimônio natural, orientar e promover programas de proteção e de recuperação ambiental (Brasil, 1998).

A conservação, proteção e recuperação ambiental, que contribuem para o bem-estar humano e para uma economia mais promissora, exigem ações efetivas de planejamento e de gestão dos recursos naturais envolvidos em cada região do país. No entanto, tudo indica que falta, em muitos programas já iniciad os em diferentes locais do Brasil e nos futuros programas, enfrentar alguns desafios de tornar as ações e os resultados mais transparentes, apresentar melhor os meios financeiros e os limites da capacitação dos parceiros e elaborar uma sólida abordagem de desenvolvimento sócio-ambiental.

U m desafio chave na gestão de recursos naturais em geral consiste em continuar a construir e reforçar a abordagem de abrangência nacional, de programas para permanecerem receptivos às prioridades comunitárias em diferentes regiões geográficas e sócio-culturais. Não menos importante é encorajar uma ampla representação dos membros de organizações governamentais e de organizações não governamentais, dos meios científicos, dos estabelecimentos de ensino superior, de associações e mesmo a inserção de indivíduos, criando-se assim ocasiões indispensáveis para a troca de idéias, exposição de pontos de vista, propostas e conclusões.

Entretanto, é necessário transformar o modelo de funcionamento das ações ambientais no 
país, procurando fortalecer sua capacidade de gestão e aperfeiçoar a responsabilidade e a informação em relação às tomadas de decisões, considerando a complexidade crescente e a urgência de problemas ambientais, o compartilhar da governança e a transparência exigida cada vez mais pela população. Este fortalecimento ajudaria às instituições governamentais de gestão ambiental a oferecer melhores serviços à população, melhores e inovadoras adaptações, manter um diálogo mais rico com a população e aperfeiçoar os resultados, visando a melhoria do meio ambiente.

Nesse sentido, os princípios de gestão integrada e participativa presentes nas políticas públicas do país, em especial a de Recursos Hídricos, devem orientar a cultura, as estruturas, os processos e a capacitação de gestão de organizações a fim de permitir alcançar os resultados em longo prazo.

No Brasil, algumas iniciativas do governo federal, de determinados estados e de comitês de bacias, além de projetos de restauração de rios financiados por instituições privadas de grande porte, têm demonstrado a necessidade de engajar a população local nas ações de planejamento e de execução. Contudo, nessas iniciativas não tem sido destacada a capacitação social como uma estratégia clara e sistemática para alcançar resultados positivos nas ações coletivas de suas local idades.

Este trabalho de pesquisa, relatado sucintamente neste artigo, é parte do marco teórico sintetizado por Limeira (2008). Foi concebido no sentido de se elucidar os conceitos teóricos sobre restauração de rios e os seus aspectos relativos à capacitação social aplicada.

Teve como objetivo principal identificar os obstáculos e oportunidades para a gestão de restauração de rios, em que se adote a capacitação social de comunidades ribeirinhas, de modo a viabilizar, nesses locais, programas de instituições públicas ou privadas em longo prazo. Pretende-se preencher algumas lacunas do conhecimento sobre a gestão de restauração de rios, tendo a capacitação social como a estratégia indispensável para se alcançar uma gestão democrática e sustentável.

\section{METODOLOGIA}

Esse estudo se constitui numa problematização de conceitos usualmente empregados para a construção do conhecimento e numa teorização sobre a gestão de restauração de rios. Existe, de fato, uma lacuna sobre o tema restauração de rios na bibliografia brasileira inclusive sobre definições básicas, como reconhecido por M achado (2008).

Conforme adverte Bordieu (apud Minayo, 2000), "a teoria da prática que aparece como condição de uma ciência rigorosa das práticas, não é menos teórica"; acrescenta ainda que o privilégio presente em toda atividade teórica supõe um corte epistemológico e um corte social e ambos governam sutilmente a realidade.

N esse sentido, foram colocados em questão os pressupostos inerentes ao objeto do estudo, isto é, a capacitação para gestão de restauração de rios, buscando-se os seus conceitos em função de sua relação com a realidade, incluindo-se as suas relevâncias.

Esse trabalho situa um quadro de preocupações essencialmente teórico. Do ponto de vista prático, o objeto de pesquisa se vincula às indagações provenientes de múltiplos interesses (de ordem lógica e sociológica). A clareza e a precisão dos primeiros passos na construção teórica decorrem de uma relação dialética entre o esforço de estabelecer marcos conceituais, os mais amplos e abrangentes possíveis, e, ao mesmo tempo, articulá-los com a prática. Para o esclarecimento da posição adotada nessa pesquisa, caracterizada como exercício de crítica teórica e prática, aplicou-se o método hermenêutico (Weller, 2007). Ou seja, na pesquisa bibliográfica realizada, foram destacadas as categorias centrais, os conceitos e as noções usadas pelos diferentes autores. Além disso, destacam-se os pressupostos teóricos e as razões práticas que subjazem aos trabalhos consultados.

\section{CONCEITOS E FUNDAMENTOS PARA CONSTRUIR A ESTRATÉGIA}

Conceitos relativos à restauração de rios e a indicadores de cobertura vegetal na gestão de recursos hídricos

Para especificar aqui o assunto de restauração de rios, é importante que sejam conhecidos vários conceitos, que são geralmente utilizados em diferentes países para designar um tratamento de combate a esta específica degradação, relacionados a seguir:

Revitalização. Compreende o processo de recuperação, de conservação e de preservação ambiental, por meio da implementação de ações integradas e permanentes, que promovam o uso sustentável dos 
recursos naturais, a melhoria das condições socioambientais, o aumento da quantidade e a melhoria da qualidade da água para usos múltiplos (MMA/ FNMA 2005);

Restauração. Refere-se a ações que envolvem o objetivo de retornar o rio à sua condição original ( $L$ WRRDC, 2000); É um complexo esforço, que começa pelo reconhecimento das alterações naturais ou induzidas pelo homem e são danosas à estrutura e às funções do ecossistema ou impede sua recuperação para uma condição sustentável (Pacific Rivers Council, 1996 apud FISRWG, 2001);

Restauração ecológica. É o processo de ajudar a recuperação e a gestão da integridade ecológica, que envolve uma vasta biodiversidade, processos ecológicos, estruturas, contextos regionais e históricos, e práticas culturais sustentáveis ( Society for Ecological Restoration -SER apud FISRWG, 2001);

Renaturalização. É a recuperação de rios e córregos de modo a regenerar o mais próximo possível à biota natural, através de manejo regular. É também preservar as áreas naturais de inundação e impedir quaisquer usos que inviabilizem tal função (Binder, 1998).

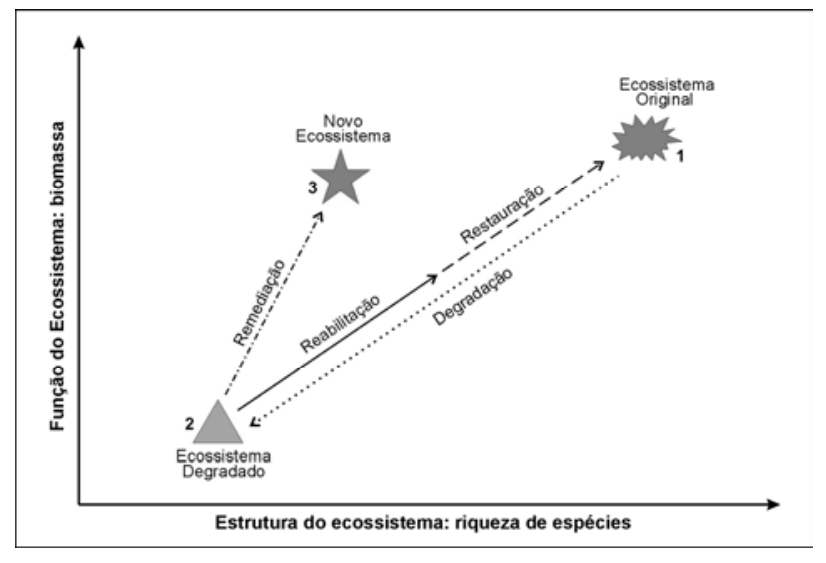

Figura 1 - Diferenças entre os conceitos de restauração, reabilitação e remediação (Adaptada de LWRRDC, 2000)

Outros conceitos como reabilitação e remediação são às vezes utilizados, mas devem ser compreendidos como ações com finalidades diferentes, conforme apresentado na figura 1 , onde 0 eixo $X$ significa a Estrutura do ecossistema associada à riqueza de espécies e 0 eixo Y a Função de produção de biomassas do ecossistema.
Reabilitação. Refere-se à manutenção apenas de alguns aspectos do rio, mas geralmente torna a sua situação mais próxima da condição natural (LWRRDC, 2000);

Remediação. Reconhece-se que as condições do rio foram tão alteradas que a condição original não seria tão relevante e almejaria uma condição inteiramente nova ( LWRRDC, 2000).

Esses conceitos obviamente sofrem influências provenientes de abordagens de diferentes áreas do conhecimento, como biologia, agronomia, antropologia, economia, entre outras. Ademais, permeiam também influências das experiências estrangeiras com linguagens e culturas diferentes. Seria necessário, então, associar o termo mais adequado às características do trabalho a ser desenvolvido.

0 conceito de restauração acima é o utilizado neste trabalho, por se identificar melhor com a idéia de um esforço coletivo direcionado à recuperação de uma condição sustentável. Vale observar que o conceito semelhante mais conhecido no Brasil atualmente ou o oficialmente utilizado pelo Ministério do Meio Ambiente, é o de revitalização (MMA/ FNMA 2005).

Além da diversidade de conceitos relativos à restauração de rios, os indicadores necessários à informação para tomada de decisão são escassos e diversificados. Para a visualização de indicadores importantes na gestão ambiental ligados à restauração de rios, pode-se citar os que foram apresentados na pesquisa realizada por Magalhães Júnior et al. (2003). Esses indicadores obtiveram os maiores índices de aprovação para uso no processo de gestão das águas nesta pesquisa. Contudo, como ressaltam os autores, "a gestão da água tem uma forte conotação política e os interesses envolvidos nos processos decisórios determinam a escolha e a utilização de indicadores". Acrescentam que, atualmente, vê-se de fato que a relevância de indicadores não tem garantido a sua efetiva operacionalização e nem a sua aplicação em avaliações ambientais de forma unânime em todas as partes do Brasil.

Salientam que 0 indicador original no painel proposto por Magalhães Júnior et al. (2003), em relação à cobertura vegetal, foi o índice de cobertura vegetal; complementarmente, foram sugeridos outros índices: Índice de perda de cobertura vegetal; Densidade espacial de fragmentos vegetais; Índice de comprimento de rios com matas ciliares em conformidade legal.

Existe uma compreensão em avaliar criteriosamente dados como os índices, pois segundo avali- 
ação do EPA (1999), não é suficiente a análise de dados ou de índices sobre o curto prazo. A capacitação social é um processo incremental, um processo em longo prazo. Seria importante, então, combinar o uso de índices com outros dados qualitativos para contextualizá-los no tempo e no espaço.

Capacitação social para restauração de rios

O conceito de capacitação social considerado pelo governo da Austrália (LWA, 2003) na sua política específica de restauração de rios é baseado na capacidade de indivíduos, de grupos e de instituições em entender e lidar com elementos restritivos e facilitadores, dimensões e questões que dirigem 0 processo de acumulação de capital, seja social, humano, natural, físico ou financeiro, o que deverá levar ( sob todas as formas) à produção de resultados desejáveis.

Esse conceito de capacitação social, para se tornar mais claro, envolve a compreensão de que absorve as definições de "capacitação", de "capital" e de "capacitação para construir", segundo o quadro teórico utilizado pelo Land \& Water Australia ( LWA, 2003). Para o LWA, a literatura sobre capacitação social cita freqüentemente cinco tipos de capital: natural, social, humano, físico e financeiro. No entanto, para projetos de restauração de rios, o LWA utilizou mais diretamente as duas formas de capital: capital social (nível comunitário) e capital humano (nível individual).

A capacitação para construir relaciona-se a alguma forma de intervenção interna ou externa dirigida ao objetivo de habilitar indivíduos ou comunidades a agir para alcançar a sustentabilidade.

Esta perspectiva de análise enfoca a capacitação na qual cientistas, governos, empresários, associações e organizações não governamentais reclamam para conhecer "o que precisa ser realizado" e são interessados em apoiar comunidades, em particular os proprietários de terra, a alcançarem seus objetivos.

Dessa forma, como um processo de desenvolvimento, a capacitação social é um processo de construção de um sistema no qual se alcançam as capacidades técnica, gerencial e financeira para assegurar consistência com a política nacional e com outros instrumentos expressos no aparato legal estabelecido.

O s três elementos básicos da capacitação, as áreas técnica, gerencial e a financeira sustentam a estrutura tridimensional do sistema. Cada elemento isoladamente é necessário, mas não é o suficiente para exercer sua função, sendo um intrinsecamente relacionado com os outros. O monitoramento, a avaliação e o planejamento estratégico podem direcionar todos os três elementos da capacitação. Cada um desses elementos pode ser definido de acordo com os resultados esperados. As definições deles são apresentadas no módulo de treinamento Developing Water System M anagerial Capacity (EPA, 2002) descritas resumidamente a seguir:

A capacitação técnica é definida como as habilidades física e operacional que um sistema requer, incluindo a adequação de infra-estrutura física, conhecimentos técnicos e pessoal capacitado. $A$ adequação técnica deve ter um claro compromisso com os padrões e com outros indicadores de performance;

A capacitação financeira é definida como a habilidade do sistema em adquirir e em gerenciar recursos financeiros suficientes que permitam ao sistema alcançar e manter compromisso com os padrões e requisitos legais;

A capacitação gerencial é definida como a habilidade do sistema em tornar-se capaz de conduzir seus relacionamentos para alcançar e manter compromisso com as exigências legais, incluindo as capacidades administrativas e institucionais.

A figura 2 a seguir mostra a importância que o planejamento tem como um instrumento gerencial para inter-relacionar os três elementos essenciais da capacitação.

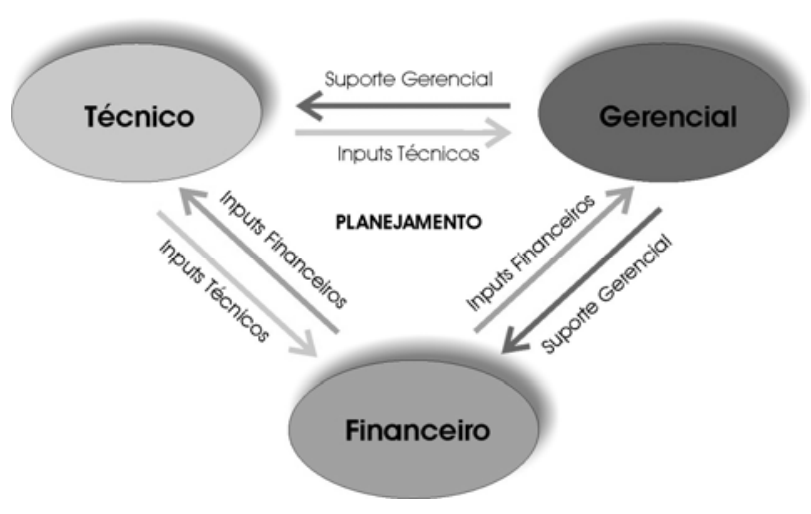

Figura 2 - 0 planejamento ajuda a manter unidos os três elementos da capacitação

Para muitos, a aplicação indiscriminada do termo capacitação social referindo-se a diversos problemas é uma fonte de preocupação. Para um melhor esclarecimento e baseando-se em alguns estudos de caso realizados pelo European Centre for Development Policy M anagement -ECDPM (2000) ressalta-se que um consenso está emergindo com base em definições abrangentes e holísticas. E apesar de 
correr o risco de somar a excessivas definições já em circulação, para o ECDPM, capacitação pode ser definida como uma demanda ou uma condição para desempenhar funções particulares ou realizar objetivos de uma maneira eficiente e sustentável. Para um indivíduo, isso pode significar uma tarefa particular. Para uma nação, pode significar uma gestão eficaz de uma economia liberal, ou participação em cooperação internacional.

\section{A credibilidade e a boa governança}

$\mathrm{Na}$ visão do economista francês Michel Camdessus, sobre temas relacionados ao uso da água no mundo, os problemas de financiamento para questões de recursos hídricos são em geral políticos e exigem uma melhor governança. Ele afirma que no Brasil e na América Latina não existe escassez de água (Camdessus, 2006).

Para soluções de problemas de financiamento de distribuição da água, por exemplo, Camdessus menciona um conceito central, cujo princípio é de financiamento descentralizado e de boa governança. Além deste, cita ainda mais dois conceitos: o primeiro, o de financiamento conjunto (público e privado) para os mais pobres, de modo que não sejam concedidos empréstimos ou garantias, mas a aceitação da condição de dar dinheiro sem pedir nada em troca. 0 segundo conceito consiste em fornecer assistência técnica adequada, educação administrativa apropriada aos responsáveis por localidades menores para que estes possam melhor gerenciar as instalações locais. N ota-se que esses conceitos emitidos por Camdessus vão ao encontro dos elementos principais do conceito de capacitação social anteriormente apresentado.

Deixa claro "que havendo implementação de métodos adequados para recuperação sustentável de custos aliada a uma boa governança, a água não vai se esgotar".

Afirma ainda Camdessus: "Em relação ao fato de o Brasil ter uma cultura administrativa vulnerável a práticas de corrupção, sugere-se introduzir mais transparência na administração local, visto que este fator é muito importante na gestão da água para que se criem condições favoráveis ao treinamento e ao ambiente propício ao investimento".

Por outro lado, é evidente que é grande a descrença no poder público no Brasil, em todas as esferas de governo. Segundo o sociólogo Juarez de Paula (2005), a maior parte dos programas e projetos nos últimos dez anos, que tem exigido algum tipo de participação popular, só existe para cumprir uma exigência na obtenção do repasse de recursos.
No entanto, ressalta que a capacidade de realização e a gestão compartilhada precisam ser conquistas da sociedade, e que a participação e o controle social são imprescindíveis para a eficácia na gestão do que é do interesse público.

A imagem da marca e a reputação, representando a credibilidade, são consideradas como componentes dos ativos intangíveis das empresas, e por que não dizer de todos os indivíduos, grupos ou organizações. Essa visão de valorizar bens intangíveis é assinalada por Cunha e Junqueira (2004), como o gerenciar da reputação, a resposta ao crescente poder de organização da sociedade civil, que não apenas gere novas pressões sobre as empresas, mas, sobretudo no setor publico, para que haja mais abertura e transparência nas relações com a sociedade, com atitudes que valorizem a ética.

Enormes dificuldades estão sendo encontradas em experiências de desenvolvimento local em várias regiões do país, quando se trata da construção de uma nova esfera pública e da criação de parcerias. Este é um dos desafios apresentados por Zapata e Parente (2005). Essas autoras destacam a importância da capacitação institucional para a gestão participativa, seja em instituições públicas, privadas ou não governamentais.

Zapata e Parente (2005) sugerem que o meIhor caminho para enfrentar dificuldades é procurar um processo de articulação crescente, a partir do reconhecimento dessas dificuldades e do envolvimento e da exposição das instituições à comunidade envolvida.

A articulação institucional é entendida como um processo, na medida em que se buscam consensos, administram conflitos e firmam parcerias de apoio a ações locais, criando uma ambiência favorável ao desenvolvimento no interior das organizações e para a construção de novas institucionalidades. Esclarecem as autoras que a parceria deve ser tratada como um relacionamento, não como um negócio.

\section{CAPACITAÇÃO SO CIAL COMO ESTRATÉGIA GERENCIAL PARA RESTAURAÇÃO DE RIOS}

Os grandes desafios do desenvolvimento sustentável para promover a restauração de rios em várias partes do mundo e particularmente no Brasil estão ligados à aquisição de novos conhecimentos, à elaboração de indicadores para tomada de decisão e 
ao estabelecimento de parcerias, principalmente com vários níveis de governo.

A necessidade de uma gestão compartilhada cuidadosa das áreas ribeirinhas e de ordenar os hábitos de utilização das terras sobre esse ecossistema pode ser ressaltada pelas seguintes razões: diminuir a erosão, melhorar a qualidade da água, manter os ecossistemas saudáveis, manter as estruturas morfológicas fluviais, equilibrar o estoque de água, diminuir pestes de insetos, aumentar o valor da propriedade rural, gerar efeitos de abrigo, criar oportunidades para a biodiversidade, atuar na retenção de nutrientes, atuar na mudança climática, aumentar estoques de peixes, servir de refúgio da biota aquática na paisagem, diminuir o crescimento de algas e possibilitar a prática do ecoturismo (LWA, 2005).

Existem diversas medidas específicas (LWA, 2005) que podem ser usadas para recuperar e proteger as terras ribeirinhas em boas condições, entre elas: i) Retenção da vegetação nativa existente e suprimir ou remover espécies e sementes invasoras; ii) Estabilização e revegetação de áreas ribeirinhas degradadas; iii) Controle e gestão dos estoques de água nas zonas ribeirinhas e do fornecimento através de sistemas de abastecimento para áreas al hures.

Sem deixar de considerar os custos da gestão de terras ribeirinhas, os benefícios a serem alcançados podem ser derivados dela e muitos problemas evitados. Na Austrália, não raro, esses benefícios em médio e em longo prazo facilmente cobrem os custos contraídos inicialmente (LWA, 2005). Diversos grupos comunitários e proprietários de terras individuais têm projetado inovações nos métodos de melhorar a gestão de terras ribeirinhas de maneira que se torne prática normal dentro das operações agrícolas.

Em termos de desempenho gerencial, a importância de programas de capacitação social como um pré-requisito para ação de projetos de restauração de rios reside no fato de que o Estado torna-se capaz de maximizar o impacto de seu dinheiro e de outros recursos. Por isso, a capacitação social pode representar uma oportunidade histórica para o Estado criar um futuro com melhores condições ambientais, a partir da existência de maiores coberturas vegetais.

Para se criar estratégias compreensivas e tornar possível estruturar pequenos sistemas, buscando alcançar e manter compromisso com as legislações relacionadas, as áreas de preservação permanente, espaços próprios para restauração de rios, deverão ser priorizadas.
Contudo, por onde o Estado deveria começar na construção dos elementos estratégicos para pequenos sistemas de restauração de rios? A resposta imediata, sem dúvida, seria iniciar com a etapa da regulamentação. Entretanto, o governo dos Estados Unidos, por exemplo, propõe uma direção estratégica que delineia cinco elementos para o desenvolvimento de capacitação social. Essa direção deve considerar solicitar o comentário público e incluí-lo quando for apropriado (EPA, 1999). Os cinco elementos são: a) Os métodos ou critérios usados para priorizar o sistema; b) Os fatores que encorajam ou impedem desenvolver a capacitação; c) Como o Estado usará autoridade e recursos para o sistema de restauração de rios; d) Como o Estado estabelecerá as linhas bases e medirá melhorias; e) Os procedimentos usados para identificar pessoas interessadas.

Estes elementos serão discutidos em detaIhes no próximo subitem. De qualquer modo, é importante abordar este processo e começar com uma abertura para soluções criativas, inovações e propostas não tradicionais, que possam assegurar um sistema de restauração de rios para todo o país.

Ressaltam-se ainda outros aspectos associados ao estudo da restauração de rios e ligados também às duas fronteiras mais importantes para os esforços de capacitação social, que são o tempo e o espaço. A capacitação pode ser vista por atores como uma parte de uma estratégia de construção nacional (o nível macro), outros vêem como o esforço de unidades organizacionais, de setores ou de funções (o nível meso) e outros, como um desenvolvimento particular local, como uma ONG, organização não governamental (o nível micro). Por conseguinte, existe uma multiplicidade de projetos e de programas em nome da capacitação social.

Observa-se, no entanto, que a criatividade tem contribuído para inovação em esforços para a capacitação social. Por exemplo, as provisões da capacitação social possibilitam ao Estado a flexibilidade para criar uma estratégia que avalie um sistema de capacitação não apenas referente ao sistema fluvial local (nascentes, veredas, córregos ou riachos), como também na abrangência de toda a bacia. Ao expandir os limites tradicionais de fronteira espacial ( o sistema local) para uma área maior de consideração (a bacia hidrográfica), novas soluções tornam-se prováveis, por exemplo, criando programa mentor, agrupando recursos no sistema para alcançar economia de escala, criando monitoramento em parcerias, entre outros.

Apoiar um sistema de capacitação já existente requer do Estado levar estratégias diferentes que devam usar diferentes instrumentos e recursos da- 


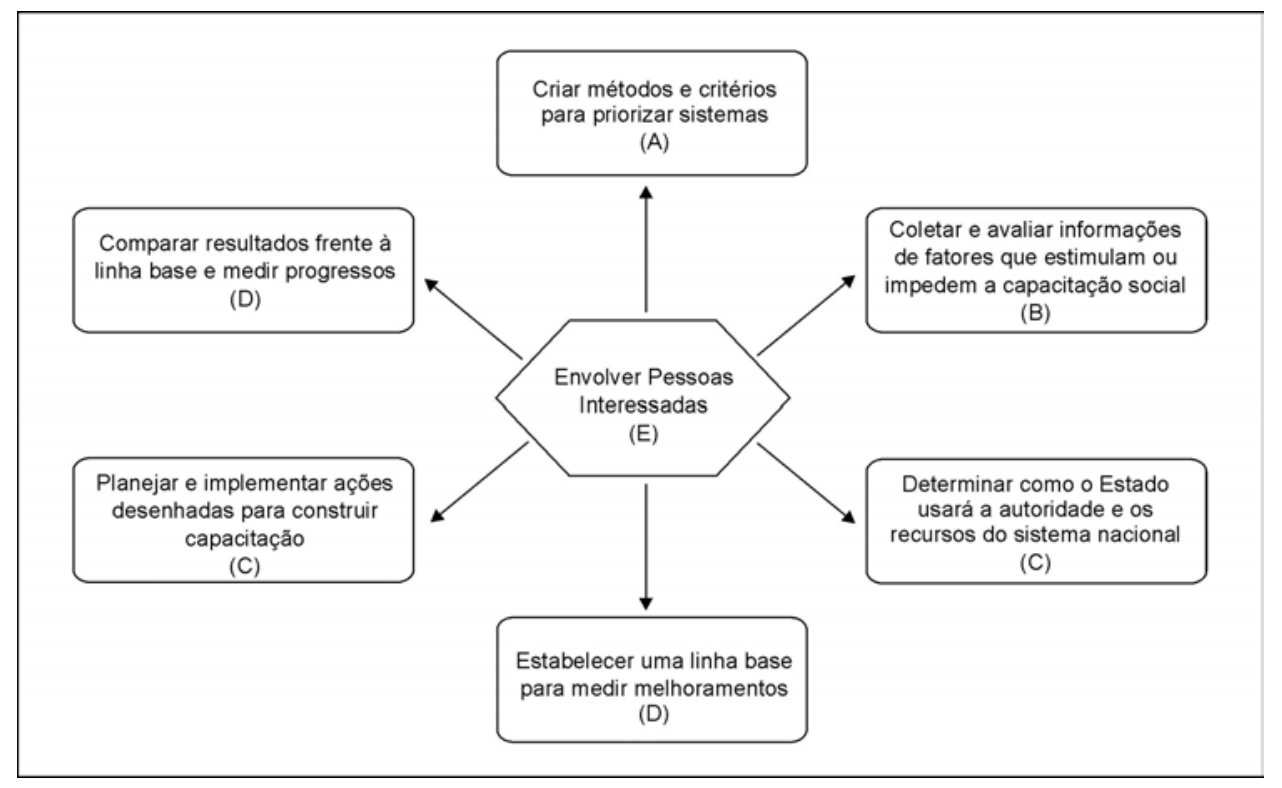

Figura 3 - Construção de uma estratégia de Capacitação Social (Adaptada de EPA, 1999)

queles requisitados para assegurar capacitação em um novo sistema. Devido a circunstâncias e características de cada Estado ou local, estes instrumentos e recursos empregados podem variar muito. Os cinco elementos programáticos são discutidos especificamente a seguir.

Construindo convergência de conceitos para uma estratégia de capacitação social

Baseando-se nos cinco elementos referidos no item anterior para construir uma estratégia de capacitação social, utilizada pela EPA (1999), como especificado na lei "Safe Drinking Water Act -Amended in 1996" para desenvolvimento de sistemas de capacitação objetivando garantir água potável de qualidade nos Estados Unidos, pode-se procurar adequar, em um caso específico, estes elementos também para as necessidades de programas em restauração de rios em nível federal e estadual. O s elementos programáticos são:

A. Os métodos ou critérios usados para priorizar sistemas: Incluem métodos ou critérios que poderiam ser usados para identificar e priorizar os sistemas de restauração mais necessitados de aperfeiçoar a capacitação técnica, financeira e gerencial;
B. Os fatores que encorajam ou impedem desenvolver a capacitação: estes incluem fatores relacionados à questão institucional, regulatória, financeira e legal que existem nos níveis federal, estadual ou local que estimulam ou impedem a capacitação social;

C. Como o Estado usará a autoridade e os recursos para o sistema de restauração de rios: os estados devem descobrir como usarão a autoridade e recursos do sistema, ou seja: i) Dar assistência aos sistemas locais de acordo com as exigências legais e regulatórias; ii) Alcançar capacitação técnica, gerencial e financeira, para estimular o desenvolvimento de parcerias entre os sistemas locais de restauração de rios; iii) Dar assistência aos sistemas locais em treinamento e certificações aos seus operadores.

D. Como o Estado estabelecerá as linhas bases e medirá melhorias: esse elemento programático potencial proporciona os instrumentos que as primeiras agências estaduais instituídas devem ter para produzir e submeter um relatório para seus governos sobre a eficácia de sua estratégia de capacitação social e o progresso realizado em direção ao aperfeiçoamento da capacitação técnica, gerencial e financeira do sistema de restauração de rios no âmbito estadual; 
E. Os procedimentos usados para identificar pessoas interessadas: os estados deveriam identificar e envolver pessoas interessadas na criação e implementação de sua estratégia de capacitação social.

A figura 3 ilustra uma maneira de como podem integrar esses cinco elementos para formar a estratégia de capacitação social.

A ordem das atividades incluídas no processo de construção da estratégia de capacitação social acima pode variar. O importante é verificar se os cinco elementos foram devidamente considerados. Observa-se especialmente que a identificação e o envolvimento de pessoas interessadas são cruciais para cada passo no processo, desde a criação até a implementação e a avaliação.

Embora um sistema nacional deva requerer que cada estado da federação considere os cinco elementos programáticos para a inclusão da estratégia de capacitação social, não deve padronizar o uso de instrumentos específicos para implementar os elementos selecionados. Cada estado é único e deve fazer decisões políticas baseadas em suas características e circunstâncias. Um sistema nacional deverá prover os estados com flexibilidade para ajustar suas estratégias às suas particularidades, as quais irão maximizar a oportunidade de cada estado para alcançar os objetivos dos programas. Os vários instrumentos podem ser desenhados para o país desenvolver programas e estratégias de capacitação social de modo flexível.

Os instrumentos precisam ser aplicados diferentemente de acordo com o tipo de sistema que está sendo considerado; um instrumento que é utilizado para desenvolver capacitação para proprietários privados pode não ser útil para capacitação social em um sistema municipal.

Algumas organizações internacionais também contribuem para o conceito de capacitação social. O Ministério do Meio Ambiente (MMA, 2006), em parceria com o World Bank Institute (WBI), atua na implementação do Plano Regional de Capacitação Ambiental -PRCA, com o objetivo de apoiar o processo de consolidação do Subprograma de Política de Recursos Naturais - SPRN, para realizar capacitações de fortalecimento das instituições, visando a gestão ambiental na Amazônia. Em 2004, o SPRN e o WBI realizaram uma oficina com participação de atores institucionais onde foram definidas seis linhas de ação: Direito Ambiental, Gestão de Conflitos, Planejamento Estratégico Participativo, Gestão Ambiental Municipal, Valorização da Floresta e Estratégias de Comunicação e de Informação. A metodologia adotada no PRCA está estruturada em duas modalidades de atividades: a primeira utiliza uma série de seminários apresentados em videoconferências interativas em rede, onde o tema é exposto e discutido com participantes em diferentes cidades. A segunda é a discussão virtual (on line) após os seminários, baseada em questões específicas do tema discutido.

Outro trabalho de construção em capacitação social pode ser observado no Programa de Ações Estratégicas para o Gerenciamento Integrado da Bacia do São Francisco e de sua Zona Costeira, conhecido como Projeto GEF São Francisco. Esse projeto, executado pela Agência Nacional da Água ANA, tem 0 apoio financeiro do Fundo Mundial para o Meio Ambiente com participação do Programa das Nações Unidas para o Meio Ambiente PNUMA e da Organização dos Estados Americanos $-O E A$. As lições já extraídas desse gigantesco trabaIho em andamento podem ser analisadas para meIhorar outras experiências no Brasil. Dentre elas, podem-se destacar três de grande importância para o entendimento dos resultados esperados em um projeto de escala espacial regional, ou que possam ser identificadas em projetos em qualquer que seja sua escala espacial ( Souza et al. 2005):

i. A participação pública está mais vinculada à cultura, aos valores e aos hábitos das pessoas, do que numa mudança global, sendo fruto estritamente da ação empreendida, necessitando, portanto, de mais estímulos que fortaleçam essa participação;

ii. A mudança de atitude é influenciada a partir da percepção do público ao serem imbuídos de responsabilidades, ficando suas reações moderadas com tendência à racionalidade na tomada de decisões;

iii. O Comitê de Bacia mostrou-se capaz de tomar decisões e incentivar o apoio e participação das comunidades locais nos temas de interesse da Bacia, exercendo assim, o seu papel de indutor dos entendimentos institucionais, agregando valores ao processo de participação pública.

Essas experiências em andamento no Brasil mostram como o movimento de influenciar a concepção da estratégia de capacitação social pode ser aberto a abordagens estrangeiras. Mostram-se também sensíveis às características culturais e históricas de comunidades locais. 
CONSIDERAÇÕES FINAIS

A partir das experiências de estratégias estrangeiras em construção de capacitação social para planejamentos ambientais, com o debate no Brasil, exploram-se as oportunidades de aprendizagem e aperfeiçoamento. Assim, surgem com mais intensidade as questões sobre as pré-condições para adotar a estratégia de capacitação social concebida como um processo em longo prazo. Observa-se que na ausência dessas condições prévias, sem dúvida sua eficácia será limitada.

Evidentemente, todas as estratégias encerram muitos diferentes pontos fortes e fracos, e, em muitos aspectos rompem barreiras, avançando para um novo campo de desenvolvimento social. 0 importante, contudo, é debater amplamente as dificuldades e os elementos favoráveis, saindo do isolamento de cada um para um engajamento no esforço conjunto de aprender através dessas experiências.

Em direção ao objetivo específico de restauração de rios, ganha-se no entendimento do grau de variação dos fatores restritivos ou favoráveis do contexto social, econômico, político e biofísico, nos quais os futuros e os atuais projetos de restauração de rios estão situados, ressaltando-se a estratégia de capacitação social e os resultados positivos que podem ser alcançados com essa estratégia.

\section{REFERÊNCIAS}

BINDER, W. "Renaturalização de Rios - Possibilidades e Limites da Engenharia Ambiental" Projeto Planágua SEMAPS/GTZ. Rio de Janeiro, RJ, Brasil, 1998. 39p.

BRASIL Lei 6.938/81 "Política Nacional do Meio Ambiente" In: Meio Ambiente: lei 9.605/98. Rio de Janeiro: Ed. Esplanada 1998, 96p.

CAMDESSUS M. "Água vale mais que petróleo" Entrevista ao Valor Econômico. Por Robsinson Borges. São Paulo. Disponível em: www.br.groups.yahoo.com/group/ ABRH - Gestão/. Acesso em: 10 fev. 2006. 7p.

CUNHA I.; JUNQUEIRA L. P. "Gestão da Sustentabilidade: Risco ambiental, Conflito, Governança e Cooperação." In: Anais do XIX Encontro Nacional de Pósgraduação em Administração. ENANPAD. 2004 CD $14 \mathrm{p}$.

ECDPM - EUROPEAN CENTRE FOR DEVELOPMENT POLICY MANAGEMENT. "Building the Base for Cooperation :Institucional Capacities and Partnerships." Issu- es Paper 3. September 2000. Disponível em: www.edcpm.com. Acesso em: 20 fev.2006. 9p.

EPA - ENVIRONMENTAL PROTECTION AGENCY - UNITED STATES. "Handbook for Capacity Development: Developing Water System Capacity Under the Safe Drinking Water Act as Amended in 1996." 1999, Disponivel em: www.epa.gov. Acesso em: 20 fev.2006. $141 p$.

EPA - ENVIRONMENTAL PROTECTION AGENCY - UNITED STATES. "Developing Water System Managerial Capacity". 2002, Disponível em: www.epa.gov. Acesso em: 10 fev. 2006. 166p.

FISRWG - FEDERAL INTERAGENCY STREAM RESTORATION WORKING GROUP -. "Stream Corridor Restoration: Principles, Process, and Practices". Published USA Government, October, 1998. Revised August, 2001. Disponivel em: http://www.usda.gov/stream restoration. Acesso em: 09 set. 2004. 630p.

LIMEIRA, M. C. M.; "Gestão Adaptativa e Sustentável: capacitação social como estratégia para restauração de rios". Tese de Doutorado em Recursos Naturais. Universidade Federal de Campina Grande, Campina Grande, Paraíba. 2008, 298p.

LWA - LAND \& WATER AUSTRÁLIA - "Assessing community capacity for riparian restoration". Published by Land \& Water Austrália, Canberra ACT 2601. July 2003. Disponivel em: www.lwa.gov.au. Acesso em: 15 mar. 2005, 55p.

LWA - LAND \& WATER AUSTRALIA . "Managing Riparian Land". Fact Sheet 1. 2005, Disponivel em: www.rivers.gov.au. Acesso em: 12 abr. 2005.

LWRRDC. LAND AND WATER RESOURCES RESEARCH AND DEVELOPMENT CORPORATION. "A Rehabilitation Manual for Australian Streams". 2000, Vol. 1. Disponível em: www.lwrrdc.gov.au Acesso em 15 mar. 2005. 192p.

MACHADO, A. T. M. "A construção de um programa de revitalização na bacia do Rio São Francisco" Revista de Estudos Avançados - USP. vol.22, no.63, p.195-210. Mai./Ago. 2008.

MAGALHÃES JUNIOR, A. P.; CORDEIRO NETTO O. d. M.; NASCIMENTO N. d. O. "Os indicadores como Instrumentos Potenciais de Gestão das Águas no Atual contexto Legal-Institucional do Brasil - Resultados de um painel de especialistas." In: Revista Brasileira de Recursos Hídricos. RBRH. Vol.8, n.4 , pp. 49-67 Out./Dez. 2003.

MINAYO, M. C. d S. "O desafio do conhecimento: pesquisa qualitativa em saúde". São Paulo: Hucitec; Rio de Janeiro: Abrasco $-7^{\mathrm{a}}$ ed. 2000

MMA/FNMA. MINISTÉRIO DO MEIO AMBIENTE. Fundo Nacional do Meio Ambiente."Recuperação e Proteção de Nascentes e Áreas que Margeiam os Corpos 
D’Água". Edital FNMA ñ 02/2005. Disponível em: www.mma.gov.br. Acesso em 20 mai. 2005. 56p.

MMA. MINISTÉRIO DO MEIO AMBIENTE. "Plano Regional de Capacitação Ambiental - PRCA. Seminários a distância e discussão virtual." Disponível em: www.mma.gov.br. Acesso em 12 mar. 2006.

PAULA. J. D. "Desenvolvimento \& Gestão Compartilhada". In: Unidade de Desenvolvimento Local do SEBRAE Nacional. 2005. 6p.

SOUZA J. L.. d.; ANJOS N.F.R. d.; VARELLA NETO P. L. "A Participação Pública no Projeto GEF São Francisco." In: Anais do XVI Simpósio Brasileiro de Recursos Hídricos. João Pessoa. PB, CD, Nov. 2005, 6p.

WELLER, Wivian. A hermenêutica como método empírico de investigação. In: $30^{a}$ Reunião Anual da ANPEd, Caxambu, MG. 2007. p. 1-16.

ZAPATA, T.; PARENTE S.;. "O Desenvolvimento Institucional e a Construção de Parcerias para o Desenvolvimento Local.". Paper para o Projeto BNDES - Desenvolvimento Local - Cooperação Técnica do PNUD. 2005 13p.

Adaptive And Sustainable Management For River Restoration: Part I - Theoretical approaches on Social Capacity

\section{ABST RACT}

It is difficult to practice the principles of decen tralization, integration and participation to the full extent These principles are essential for effective water resources management. The reason is the clearly predominant situation related to the lack of investments in social qualification. Social capacity is understood as the capacity of individuals, groups and institutions to produce desirable re sults. As a process of construction of a system, in which technical, managerial and financial capacities are achieved, social capacity-building is seen as a strategy that can be developed through an open and adaptive manage ment. This managerial strategy is reviewed and analyzed here, from the perspective of giving greater credibility and confidence to managers of en vironmental projects, especially in river restoration projects. The role of the State is highlighted attempting to obtain the convergence of concepts and coherent actions as a basic preliminary stage in seeking effective management of river restoration projects. Keywords: river restoration, social capacity, strategic management. 